\title{
Synchronous Association of Two Types of Indolent Lymphomas
}

\author{
MARIANA ASCHIE ${ }^{1,2,3}$, ANDREEA GEORGIANA STOICA ${ }^{1,3}$, ANCA FLORENTINA MITROI ${ }^{2,3 *}$, GEORGETA CAMELIA COZARU ${ }^{2,3}$, \\ GABRIELA STANCIU ${ }^{4}$, ANCA CHISOI2,3 \\ ${ }^{1}$ Ovidius University of Constana, Faculty of Medicine, 1 University Alley, 900470, Constana, Romania \\ ${ }^{2}$ Ovidius University of Constana, CEDMOG Center, 145 Tomis Blvd., 900591, Constana, Romania \\ ${ }^{3}$ Clinical Emergency County Hospital of Constana, 145 Tomis Blvd., 900591, Constana, Romania \\ ${ }^{4}$ Ovidius University of Constana, Faculty of Applies Sciences and Engineering, 124 Mamaia Blvd., 900597, Constanta, Romania
}

\begin{abstract}
Small lymphocytic lymphomas (SLL) and lymphoplasmacytic lymphomas (LPL) are part of indolent nonHodgkin's lymphoma. LPL of the skin is very rare and synchronous association of two types of indolent lymphomas is extremely rare. We report the case of 75 years old male patient diagnosed with two types of indolent non-Hodgkin's lymphoma, lymphoplasmacytic lymphomas of the skin associated with nodal small lymphocytic lymphomas. We present this unique case with a review of the literature of synchronous nonHodgkin lymphomas highlighting the clinical, pathological and genetic methods involved in the diagnosis.
\end{abstract}

Keywords: indolent lymphoma, small lymphocytic lymphoma, lymphoplasmacytic lymphomas

Malignant lymphomas are a heterogeneous group of tumors of the lymphoid system which can involve any organ or tissues. These are divided into two major categories according to actual classification: Hodgkin's lymphoma (HL) and non-Hodgkin's lymphoma (NHL) [1]. $\mathrm{NHL}$ is a malignancies characterized by a monoclonal proliferation of B-cell or rarely T-cell [2]. Clinically NHL can be classified in indolent, aggressive or highly aggressive malignancies $[3,6]$. Small lymphocytic lymphomas (SLL) and lymphoplasmacytic lymphomas (LPL) are part of indolent NHL, according to World Health Organization classification [4].

Skin involvement in malignant lymphomas is relatively rare [5]. Lymphoplasmacytic lymphoma of the skin is extremely rare, also as association of two types of primary indolent lymphomas.

Here we describe the case of an old man patient diagnosed with two types of simultaneous indolent NHL, lymphoplasmacytic lymphomas of the skin associated with nodal small lymphocytic lymphomas, discussing the clinical, pathological and genetic methods involved in the diagnosis.

\section{Experimental part}

A 75 years man was hospitalized in Department of Hematology of Emergency Clinical County Hospital of Constanta, for establishing the etiology of left cervical lymphadenopathy appeared 1 month before.

The patient had a history of controlled severe arterial hypertension (grade III), atrial fibrillation with congestive heart failure class III NYHA, myocardial infarction, type II diabetes mellitus insulin dependent and cholelithiasis.

His recent history included a lesion of the upper lip, initially diagnosed and treated as herpes, with unfavorable outcome.

Clinical examination showed purpuric rashes of the lower limbs, a $5 / 3.5 \mathrm{~cm}$ diffuse tumor of the upper lip infiltrated the nose, ulcerated with serohematic crust and seropurulent deposit formation (figure 1). The clinical evaluation for peripheral adenopathy showed a $2 \mathrm{~cm}$ left cervical lymphadenopathy, mobile and unpainful. Splenomegaly with lower splenic pole expended $3 \mathrm{~cm}$ under the ribs, was also present.

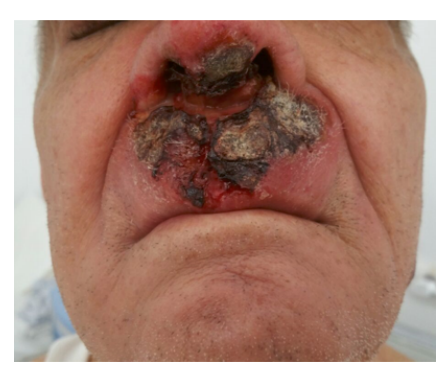

Fig.1. Lesion of the upper lip

A complete blood test evaluation was done. Laboratory investigations showed that white blood count, hemoglobin, platelets, erythrocytes sedimentation rate, hepatorenal function, serum immune electrophoresis were all in normal range. LDH (196U/l) and uric acid ( $8.8 \mathrm{mg} / \mathrm{dL}$ ) were slightly increased.

Abdominal ultrasound reveled liver normal in size and heterogeneous in echotexture, with $12 \mathrm{~mm}$ portal vein, gallstones, spleen measuring approximately $170 \mathrm{~mm}$ and preaortic adenopathies in average $13 \mathrm{~mm}$ in their greatest dimension.

A computed tomography (CT) scan revealed the presence of pathologic adenopathies in the mediastinum.

The biopsies were taken from the left cervical lymphadenopathy and from lesion of the upper lip.

On gross examination la malignant lymph node was enlarged about $2.5 \times 1.8 \times 1.2 \mathrm{~cm}$, with polycyclic contour, whitish color and medium consistency.

Histologically, the malignant node presented the effacement of nodal architecture, proliferation of small and medium malignant lymphoid cell and several mitosis (fig. 2).

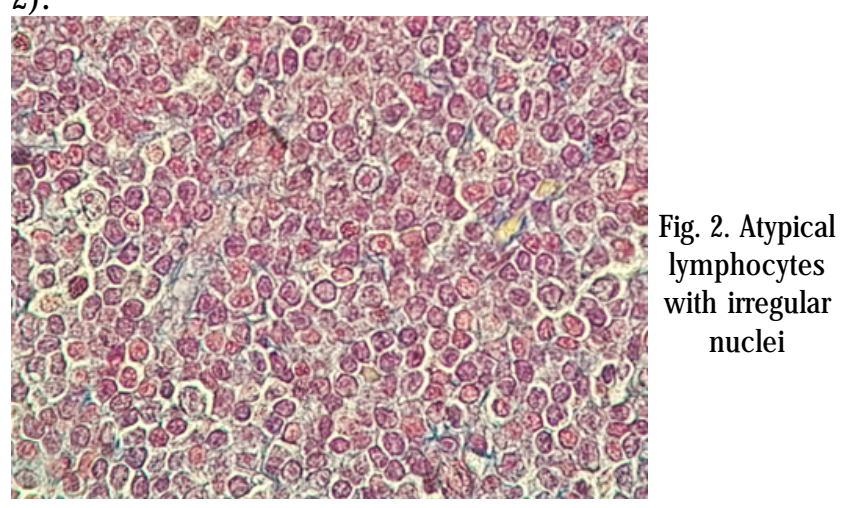


Immunohistochemistry was performed on formalin fixed, paraffin embanded tissues section using Biocare MATCH 4 detection system according to manufacturer instructions and counterstained with haemathoxylin. We determined on serial section the expression of $C D 20, \mathrm{Ki}$ 67, CD 79a and BCL6using the following antibodies: Mouse Monoclonal Anti-Human CD20 (clone L26), Mouse Monoclonal Anti-Human Ki-67(clone MIB-1), Mouse Monoclonal Anti-Human Ki-67(clone HM47/A9) and Mouse Monoclonal Anti-Human BCL6 (clone PG-B6P). The immunostainings were evaluated at 40x magnification.

CD20 expression was moderately positive showing membranous staining pattern (fig. 3). Ki- 67 was positive in 25-30\% (figure 4). CD79a expression was strong positive showing membranous staining pattern (figure 5) and BCL6 expression was negative (fig. 6).

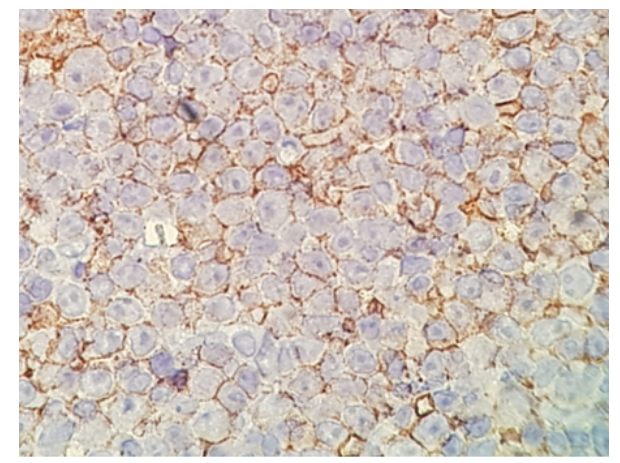

Fig. 3. CD20 moderately positive showing membranous staining pattern

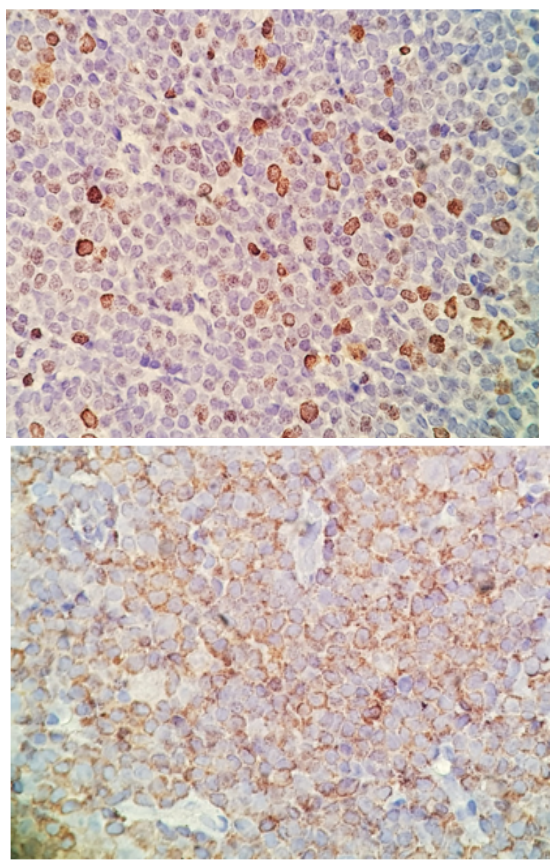

Fig. 4. Ki 67 25-30\% positive

Fig.5 CD79 a strong positive showing membranous staining pattern

Fig. 6 BCL 6 negative

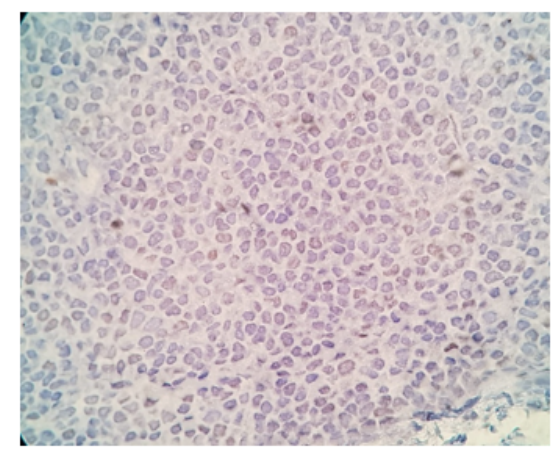

Histopathology and immunohistochemistry findings on lymph node biopsy were suggestive for small lymphocytic lymphomas.

On gross examination the biopsy of the upper lip presented irregular surface, yellowish gray color and slightly increased consistency.
Histologically, the biopsy of the upper lip showed intense proliferation of lymphoid adult cells with central and hyperchromatic nucleus, significant cellular atypia, with nodular and diffuse disposition (fig. 7). Mitotic figures were scant (fig. 8).

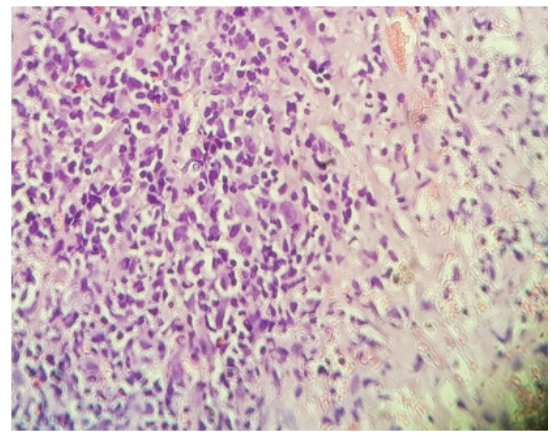

Fig. 7 Atypical Iymphocytes with diffuse disposition

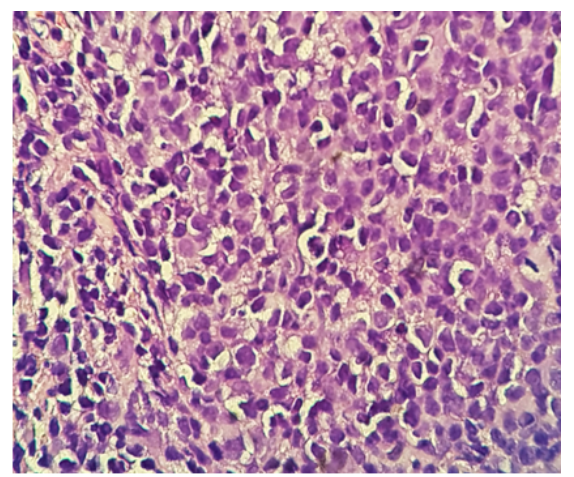

Fig.8 Rare mitosis

Because histopathology findings were suggestive for lymphoplasmacytic lymphoma, we further performed MYD88 L265P mutation analysis. DNA was isolated form formalin fixed, paraffin embedded tissue block and real time PCR for MYD88 L265P was performed using qBiomarker somatic mutation assay for MYD88-85940 (Qiagen) according to manufacturer instruction on the Applied Biosystems 7500 Fast. This assay is composed by two PCR reactions: one specific for MYD88 L265P mutation and one as reference, for non-mutated portion of MYD 88 gene. A CT values was calculated for the mutant and the reference and a $\triangle C T$ was calculated $(\triangle C T=C T$ mutant$C T$ reference). The cutoff of $\Delta C T \leq 10$ positive mutation. Our case was positive for MYD88 L265P mutation that confirms the diagnosis of lymphoplasmacytic lymphoma.

\section{Results and discussions}

We reported the case of a male patient diagnosed with two types of synchronous indolent NHL: nodal small lymphocytic lymphomas associated with lymphoplasmacytic lymphomas of the upper lip.

Small lymphocytic lymphoma is a type of indolent NHL, according to 2016 World Health Organization classification, and is viewed as similar entity with chronic lymphocytic leukemia [4]. Chronic lymphocytic leukemia is used in cases which presents lymphocytosis and small lymphocytic lymphoma in cases with nodal, spleen or extramedullary involvement and without leukemia [7]. The histological features and immunological profile of lymph node biopsy in our case were consistent with the diagnosis of SLL.

LPL is defined as a neoplasm of small B lymphocytes with plasmacytic differentiation usually involving bone marrow and sometimes lymph node and spleen [4]. The other organs which can be involved in LPL are skin, lungs and gastrointestinal tract [8]. LPL does notfulfill the criteria for any other small B-cell lymphoid neoplasm that may also had plasmacytic differentiation. MYD88 L265P mutation is found in $90 \%$ of LPL and Waldenstrom 
macroglobulinemia [9]. The histological features and mutation analysis of MYD88 of upper lip biopsy in our case were consistent with the diagnosis of LPL. LPL of the skin is very rare and are only few cases cited in the literature.

Our patient presented nodal small lymphocytic lymphomas associated with lymphoplasmacytic lymphomas of the upper lip, which is extremely rare. To our knowledge, there have been only three previously reported cases of coexisting of two types of NHL indolent lymphomas, that were MALT lymphomas and follicular lymphoma of the gastrointestinal tract [10-12], and no previously reported cases of nodal SLL and LPL of the skin. Recent studies suggest that both types of disorders can have the same clonal origin [13].

\section{Conclusions}

In this paper author showed an unsual case of simultaneous occurrence of two types of indolent NHL. The number of cases reported is to small for a meaningful analysis and conclusions about prognosis. In our case the associated comorbidities and consequent patient's premature death prevented any chemotherapeutic approach.

\section{References}

1.ASCHIE, M., Limfoame maligne non-hodgkiniene, 2, Academy of Medical Sciences Publishing, Bucuresti, 2011, p: 67-70
2.GHINEA, M.M., ADAM, T., Hematologie practica, 2, Muntenia Publishing, Constana, 2003, p: 227

3.KOC, O., WILSON, W., Clinical Hemathology, Mosby-Elsevier, 2006, p: 579-595

4.SWERDLOW, S., CAMPO, E., PILERI, S., LEE HARIS, N., STEIN, H., SIEBERT, R., ADVANI, R., GHIELMINI, M., SALLES, G., ZELENETZ, A., JAFFE, E., Blood, no 127, 2016, p:2375-2390

5.TADASHI, T., Case Rep. in Clin. Pathol.,3, no. 3, 2016, p: 31-37

6.KING, R., KURTIN, P., Hematopathology, Elsevier, 2017, p: 213-220

7.LIN, P., BUESO-RAMOS, C., WILSON, C.S., Am J Surg Pathol, 27, no 8, 2003, p: 1104-1113

8.MASCARO, J.M., MONTSERRAT, E., ESTRACH, T., Br J Dermatol, 106, 1982, p: $17-21$

9.TREON, S.P., XU, L., ZHOU, Y., LIU, X., CAO, Y., SHEELY, P., MANNING, R.J ., PATTERSON, C.J ., TRIPSAS, C., ARCAIN, L., PINKUS, G.S., RODIG, S.J ., SOHANI, A.R, HARRIS, N.L., LARAMIE, J.M., N Engl. J Med., 367, no 9, 2012, p: 826-33

10.TANG, Z., JING, W., LINDEMAN, N., Arch Pathol Lab Med, 128, no 9, 2004, p: 1035-8

11.ESHRA, A., AL-HENDAL. A., AL-ENZI, M., Gulf J Oncolog., 1, no 8, 2010, p: 39-43

12.BROHL, A., SONG. J., LIEBERMAN, R., GAUSE, B., Am J Ther., 20, no 5, 2013, p: 549-553

13.LEE, S.E., KANG, S.Y., YOO, H.Y., KIM, S.J ., KIM, W.S., KO, Y.H., Oncotarget, 7, no 11, p: 12359-71

Manuscript received: 24.08 .2018 